\section{SPD-041 QUANTITATIVE EVALUATION AND ECONOMIC IMPACT OF MEDICINE SHORTAGES IN A TEACHING HOSPITAL}

V Goncette*, V Crickboom, C Defourny, B Gérardy, D Maesen. Centre Hospitalier Universitaire De Liège, Pharmacy, Liège, Belgium

10.1136/ejhpharm-2021-eahpconf.24

Background and importance In recent years, the incidence of medicine shortages (MS) has rapidly increased at the international level. These supply problems can affect the quality of patient care, due to potential interruption of treatment and, therefore, constitute an important issue for hospital pharmacists.

Aim and objectives This study aimed to analyse MS and quantify their economic impact.

Material and methods A retrospective observational study was conducted in a 1015 bed teaching hospital, from April 2018 to September 2020. It was based on a spreadsheet that was updated manually on a weekly basis for MS. Quantitative indicators were: (a) number of MS and the drugs involved; (b) duration of MS; (c) classification of the pharmaceutical interventions to manage MS; (d) economic impact of MS; and (e) time devoted to MS weekly analysis.

Results Analysis of the collected data showed that:

a. 706 MS were reported and concerned 459 drugs.

b. Average time to restore availability was 60 days. Median duration was 33 days.

c. The pharmaceutical strategies to solve MS were displayed as:

- No action was needed due to sufficient stock available at the pharmacy for $55.2 \%$ of MS.

- Replacement by the same drug (same active ingredient, same dosage, same pharmaceutical form, different packaging and/or different pharmaceutical company) for $16.8 \%$ of MS.

- Replacement by a similar drug (same active ingredient, different dosage and/or pharmaceutical form) for $14.0 \%$ of MS.

- Replacement by an alternative drug (different active ingredient) for $6.6 \%$ of MS.

- Foreign medicine importation for $6.9 \%$ of MS.

- Restricted use in a limited number of wards for $0.3 \%$ of MS.

d. The hypothetical cost was $984533 €$ (based on the prices with the regular suppliers), if no MS had occurred. The estimated cost due to MS was $1633340 €$ (based on the prices of the pharmaceutical strategies used).

e. Management of MS required two full time equivalents: one pharmacist and one pharmaceutical technical assistant (cumulative annual remuneration of $128000 €$ ).

Conclusion and relevance These results suggested that MS generated an annual cost of $395761 €$ for our hospital. Strategies to minimise the effects of MS should be implemented.

\section{REFERENCES AND/OR ACKNOWLEDGEMENTS}

Acknowledgements to Manuela Azzolini and Sarah Fadhil, pharmaceutical technical assistants, for their participation in the data collection, and to Guillaume de Marchin, IT specialist, for the extraction of the drug prices presented in this work.

Conflict of interest No conflict of interest

\section{SPD-042 MEDICAL DEVICE'S ACTIVE VIGILANCE OF THE PHARMACIST IN THE DIGITALISATION OF INTRAOCULAR LENSES LOGISTIC PATH}

${ }^{1} \mathrm{M}$ Elena*, ${ }^{1} \mathrm{R}$ Dutto, ${ }^{1} \mathrm{M}$ Mondini, ${ }^{1} \mathrm{M}$ Viglione, ${ }^{1} \mathrm{M}$ Cavallo, ${ }^{1} \mathrm{E}$ Bastonero, ${ }^{2} \mathrm{C}$ Fruttero. ${ }^{1}$ Hospital Pharmacy, Ao Santa Croce E Carle, Cuneo, Italy; ${ }^{2}$ Director of Hospital Pharmacy, Ao Santa Croce E Carle, Cuneo, Italy

\subsection{6/ejhpharm-2021-eahpconf.25}

Background and importance Intraocular lenses (IOLs) are prosthetic medical devices (PMDs) used for the treatment of cataracts. The pharmacist is often the professional person able to guarantee the success of the PMD management path during all phases: acquisition, stock management and correct use. Active vigilance of the PMDs, digitalisation and collaboration with the different professionals (ophthalmologist, operating room nurse, administrative assistant) can improve the logistic path.

Aim and objectives The purpose of the project conducted by the pharmacist was to improve the digitalisation of the path for PMDs to increase traceability and safety through active medical device vigilance.

Material and methods Since the second half of 2019, evaluation of the efficiency of the PMD supply chain has been underway. Management has been entrusted to pharmacy, which deals with their coding and uploading to the management programme using barcodes with storage of serial numbers (SNs) and expiration dates. This new PMD management downloads to patients and to user cost centres the specification of the IOLs (dioptre and $\mathrm{SN}$ ) with a concomitant computerised reorder to restore the deposit account (DA). If it is necessary to return the IOL to the company for any reason, it must be downloaded from the warehouse, passing through the pharmacy.

Results In 2019, 3094 IOLs of 18 different models were implanted. In $95 \%$ of patients (2918 implants), we used only two models. Between October and November 2019, 98.5\% of the IOLs in the hospital on the DA were encoded and uploaded to the management programme (eight models with 332 different codes). This allowed an acceleration of DA recovery, more traceability of the implants and easier report data.

Between January and November 2019, 2879 IOLs were implanted with no incident report received. Between December 2019 and February 2020, 772 IOLs were implanted; of these, six defective IOLs were returned to the pharmacist who provided a report of the incident to the Ministry of Health. The problems concerned defects of the pre-loaded IOL injectors.

Conclusion and relevance The IOL project managed by the hospital pharmacy, in addition to a logistic improvement, has allowed further investigation into the causes of their return and has encouraged the ophthalmologist to point out non-compliances. The project slowed down during the COVID emergency but will be extended to other types of PMDs.

\section{REFERENCES AND/OR ACKNOWLEDGEMENTS}

Conflict of interest No conflict of interest 